\title{
A cadaveric study of brachial artery and its variations with its ontogenic basis: An anatomical perspective
}

\author{
Monika Lalit *1, Sanjay Piplani ${ }^{2}$.
}

${ }^{{ }_{1}}$ Professor, Department of Anatomy, Sri Guru Ram Das Institute of Medical Sciences \& Research (SGRDIMS\&R), Amritsar, Punjab, India.

${ }^{2}$ Professor, Department of Pathology, Sri Guru Ram Das Institute of Medical Sciences \& Research (SGRDIMS\&R), Amritsar, Punjab, India.

\section{ABSTRACT}

Introduction: Conventional knowledge of the brachial artery, the principal artery of the upper limb \& its branches has played a major role in vascular surgeries. Literature along with various cadaveric \& clinical studies suggest that brachial artery vary widely in origin, course and branching pattern. The great variability of this arterial pattern may be attributed to the failure of regression of some paths of embryonic arterial trunks. Anatomical knowledge of this principal artery and its variations has many clinical implications especially in surgeries related to orthopedic and vascular re-constructive procedures.

MATERIALS AND METHODS: The present study was conducted on 56 upper limbs of different age group and sex (19 Male and 9 Female) The brachial arteries were identified and branching pattern and relations of the brachial artery with brachial plexus in arm was observed and presence or absence of variations were documented.

Results: Out of 56 upper limbs studies, 53 (94.64\%) limbs showed normal morphological pattern of brachial artery, 3 (5.35\%) limbs showed superficial brachial artery, 1 limb (1.78\%) showed tortuous and SBA with trifurcation into radial artery, ulnar artery and common interosseous artery in the cubital fossa.

Conclusion: The study of Brachial artery and variation in its course and branching pattern is clinically important for surgeons, ortho-paedicians operating on the supracondylar fracture of humerus and radiologists performing angiographic studies on the upper limb.

KEY WORDS: Common Interosseous Artery, Median Nerve, Superficial Brachial Artery, Trifurcation, Ulnar Artery.

Corresponding Author: Dr. Monika lalit, Professor, Department of Anatomy, Sri Guru Ram Das Institute of Medical Sciences \& Research (SGRDIMS\&R), Amritsar, Punjab, India.

Ph No.- 9814325454 E-Mail: monika.lalit@yahoo.com

Access this Article online Journal Information

\section{Quick Response code International Journal of Anatomy and Research}

ISSN (E) 2321-4287 | ISSN (P) 2321-8967

https://www.ijmhr.org/ijar.htm

DOI-Prefix: https://dx.doi.org/10.16965/ijar

Article Information

Received: 09 Oct 2020

Peer Review: 09 Oct 2020

Revised: None
Accepted: 13 Nov 2020
Published (O): 30 Jan 2021
Published (P): 05 Mar 2021

DOI: $10.16965 /$ ijar.2020.233

\section{INTRODUCTION}

Brachial artery, the principal artery of the arm, begins as a continuation of the axillary artery at the distal border of the tendon of teres major muscle by accompanying the median nerve, enters into cubital fossa. Under the cover of bicipital aponeurosis, it divides into ulnar and radial arteries anteromedial to the neck of the radius. Common interosseous artery arises from the ulnar artery which redivides into anterior and posterior interosseous arteries [1].

At first it is medial to the humerus but gradually spirals anterior to it until it lies midway between the humeral epicondyles. Its pulsation can be felt throughout [2] and blood pressure and pulsed doppler ultrasonographic measurements are routinely assessed through 
distal part of brachial artery [3]. Conventional knowledge of the brachial artery \& its branches have played a major role in vascular surgeries involving these vessels. Literature along with various cadaveric \& clinical studies suggest that brachial artery vary widely in origin, course and branching pattern like superficial brachial artery, tortuosity or trifurcation into radial, ulnar and common interosseous arteries.

The superficial brachial artery (SBA) originates from the axillary artery and runs superficial to the median nerve and may present a superficial pulse [4]. The superficial course of these arteries may be mistaken for veins and hazardous to venaepuncture during intravenous intervention, injections, infusions and draining of blood [5]. and may lead to intraarterial injections or ligature instead of vein in cubital fossa [6]. It may also result in disastrous conditions like gangrene or loss of the hand and the results may be disastrous, like gangrene or loss of the hand [7]. Tortuousity or loops and acute bends of the brachial artery or its branches is also one of the cause of access failure in coronary interventions which may occlude the vessels causing ischemia [8]. In current study, we have tried to elaborate the current existing knowledge regarding, the course \& branching pattern of brachial artery. The knowledge of such variations is of immense significance for clinical diagnosis and surgical management of diseases of upper extremities. It is also important for nephrologists and surgeons to be aware of these arterial variations because using these anomalous arteries to establish arterio-venous access can be considered viable alternative route in some instances [9]. Knowledge of such unusual variations or deviations in brachial artery is also important for Radiologists to reduce diagnostic \& therapeutic errors. Hence Thus, the present study is aimed to observe the normal branching pattern of brachial artery and its variations in terms of course and branches arising from the brachial artery.

\section{MATERIALS AND METHODS}

Material for the present study consisted of 56 limbs from 28 cadavers of North Indian origin of different age group and sex (19 Male and 9 Female). The limbs were made in the department of Anatomy for dissection purpose for first year medical students at Sri Guru Ram Das Institute Of Medical Sciences and Research (SGRDIMSAR), Amritsar, Punjab. The upper limb was meticulously dissected to study the course \& branching pattern of brachial artery using standard procedure. [10] The brachial arteries were identified and traced proximally to the continuity with axillary artery at the level of lower border of teres major. and distally in the cubital fossa, upto its bifurcation. The branching pattern and relations of the brachial artery with branches of lateral and medial cord or brachial plexus in arm was observed. In each cadaver, both the upper limbs were dissected to note the presence or absence of any variations and if any, whether present unilateral or bilateral. The photographs were taken to document the observed variations.

\section{RESULTS}

In the present study, among 56 upper limbs studied, 53 (94.64\%) limbs showed normal brachial artery and its branching pattern. The brachial artery arose as a continuation of third part of axillary artery at the inferior border of teres major muscle, was crossed superficially by the median nerve crossed in front of the artery. All the other branches were seen taking normal origin from brachial artery in the upper arm. (Table 1,2) i.e. The profunda brachii artery arose from the postero-medial aspect of the proximal part of the brachial artery distal to teres major muscle, superior ulnar collateral artery arose a little distal to the middle of the arm and inferior ulnar collateral artery arose proximal to the elbow. Normal termination of artery into radial and ulnar arteries at the level of neck of radius in the cubital fossa was observed. 3 (5.35\%) upper limbs exhibited variations in brachial artery in the form of superficial brachial artery and trifurcation of brachial artery into radial artery, ulnar artery and common interosseous artery was observed in $1.78 \%$ of cases. (Table 1). 
Table 1: Incidence of morphology and variations of brachial artery in arm in the present study (2019).

\begin{tabular}{|c|c|c|c|c|c|c|}
\hline \multirow{2}{*}{ S No. } & \multirow{2}{*}{$\begin{array}{l}\text { Total } \\
\text { Limbs }\end{array}$} & \multirow{2}{*}{$\begin{array}{c}\text { Morphology \& } \\
\text { Variations }\end{array}$} & \multirow{2}{*}{$\begin{array}{l}\text { Number of } \\
\text { Variations }\end{array}$} & \multicolumn{2}{|c|}{ Side } & \multirow{2}{*}{$\begin{array}{c}\text { Incidence } \\
\text { (\%) }\end{array}$} \\
\hline & & & & Right & Left & \\
\hline 1 & \multirow{3}{*}{56} & Normal & 53 & 25 & 28 & $94.64 \%$ \\
\hline 2 & & SBA & 3 & $3(\mathrm{M})$ & - & $5.35 \%$ \\
\hline 3 & & $\begin{array}{l}\text { Tortuous and } \\
\text { Trifurcation of SBA }\end{array}$ & 1 & $1(\mathrm{M})$ & - & $1.78 \%$ \\
\hline
\end{tabular}

M-Male, F-Female

Table 2: Comparison of incidence of Normal Brachial Artery.

\begin{tabular}{|clccc}
\hline S No. & \multicolumn{1}{c}{ Author } & Year & $\begin{array}{c}\text { No of } \\
\text { Limbs }\end{array}$ & $\begin{array}{c}\text { Incidence of Normal } \\
\text { Pattern of Brachial } \\
\text { artery (\%) }\end{array}$ \\
\hline 1 & Uglietta \& Kadir [11] & 1989 & 100 & $91 \%$ \\
\hline 2 & Rodriguez-Niedenführ [12] & 2001 & 384 & $77 \%$ \\
\hline 3 & Patnaik et al. [13] & 2002 & 50 & $82 \%$ \\
\hline 4 & $\begin{array}{l}\text { Murugapermal and } \\
\text { MelaniRajendran [14] }\end{array}$ & 2014 & 50 & $96 \%$ \\
\hline 5 & Shivanal \& Gowda [15] & 2015 & 50 & $84 \%$ \\
\hline 6 & Jayasree \& Reddy [16] & 2017 & 50 & $94 \%$ \\
\hline 7 & Present Study & 2019 & 56 & $94.64 \%$ \\
\hline
\end{tabular}

Variation 1: The variation was observed in the Right Arm of a 54 year old Male cadaver. The Axillary artery in its third part gave the profunda brachii artery and continued as the brachial artery which crossed the median nerve superficially from the medial to the lateral side, in the middle of the arm, as the superficial brachial artery. It was called superficial brachial artery by Adachi (1928) as it runs superficial to median nerve and replaces the main trunk. No such or other variation was observed on the left side of the cadaver. (Figure 1) (Table 3)

Fig. 1: Superficial Brachial artery in the Right Arm Crossing Superficial to Median Nerve.

SBA- Superficial Brachial Artey, AA-Axillary Artery, MN-Median Nerve, UN-Ulnar Nerve,

MCN-Musculocutaneous Nerve, MC-Medial Cord, PC-Posterior Cord, LC-Lateral cord.

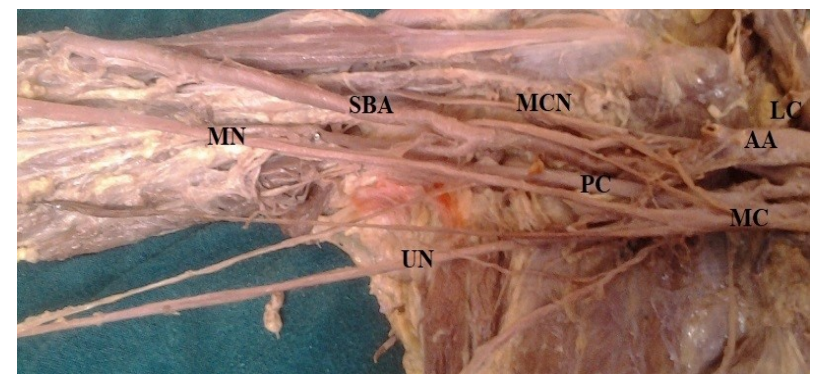

Variation 2: In the right upper limb of a 43 year old male cadaver, the brachial artery had a superficial course in the arm along the medial aspect of biceps brachii The Axillary artery in its third part gave the profunda brachii artery and continued as the brachial artery which crossed the median nerve superficially from the medial to the lateral side, in the middle of the arm, as the superficial brachial artery. No such or other variation was observed on the left side of the cadaver. (Figure 2) (Table 3)

Fig. 2: Superficial Brachial artery in the Right Arm Crossing Superficial to Median Nerve.

SBA- Superficial Brachial Artey, AA-Axillary Artery, MNMedian Nerve, MCN- Musculocutaneous Nerve, LCLateral cord, MC-Medial Cord.

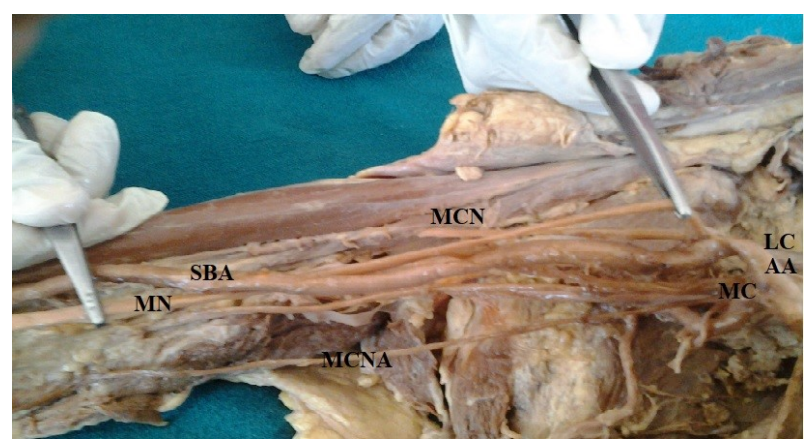

Table 3: Comparison of Incidence of Superficial Brachial Artery(SBA).

\begin{tabular}{|clccc|}
\hline S No. & \multicolumn{1}{c}{ Author } & Year & $\begin{array}{c}\text { No of } \\
\text { Limbs }\end{array}$ & $\begin{array}{c}\text { Incidence of SBA } \\
\text { artery (\%) }\end{array}$ \\
\hline $\mathbf{1}$ & Poirier [21] & 1886 & - & 6 \\
\hline $\mathbf{2}$ & Linell [22] & 1921 & - & 6 \\
\hline $\mathbf{3}$ & Nakatani et al. [26] & 1996 & - & 1 case \\
\hline $\mathbf{4}$ & Kapur et al. [23] & 2000 & - & 5 \\
\hline $\mathbf{5}$ & Patnaik et al. [13] & 2002 & - & 6 \\
\hline $\mathbf{6}$ & Yang et al. [24] & 2008 & 304 & $12.20 \%$ \\
\hline $\mathbf{7}$ & Singla and Lalit [18] & 2011 & - & 1 Case \\
\hline $\mathbf{8}$ & Kachlik et al. [25] & 2011 & 130 & $5 \%$ \\
\hline $\mathbf{9}$ & Kaur et al. [27] & 2011 & - & 1 case \\
\hline $\mathbf{1 0}$ & Alfaouri-Kornieieva [28] & 2013 & - & 1 case \\
\hline $\mathbf{1 1}$ & Present Study & 2019 & 56 & $5.35 \%$ \\
\hline
\end{tabular}

Variation 3: The variation was observed in right arm of a 52 year old male cadaver in the form of trifurcation of superficial and tortuous brachial artery. Axillary artery in its third part gave profunda brachii artery and continued at the lower border of teres major as brachial artery which crossed the median nerve superficially from medial to lateral side in middle of arm as superficial brachial artery. The artery was tortuous throughout its course. In the cubital fossa, at a distance of $3.0 \mathrm{cms}$ from intercondylar line, at the level of neck of radius, instead of bifurcating into radial and ulnar arteries, it trifurcated into radial, ulnar and common interosseous arteries. No such variation was observed in the left upper limb. (Figure 3) (Table 4) 
Fig. 3: Superficial and Tortuous Brachial artery in the Right Arm Showing Trifurcation into Radial Artery, Ulnar Artery and Common Interosseous Artery. SBA-Superficial Brachial Artey, RA-Radial Artery, UA-Ulnar Artery, CIACommon Interosseous Artery, $\mathrm{AA}=$ Axillary Artery, $\mathrm{MN}$ Median Nerve.

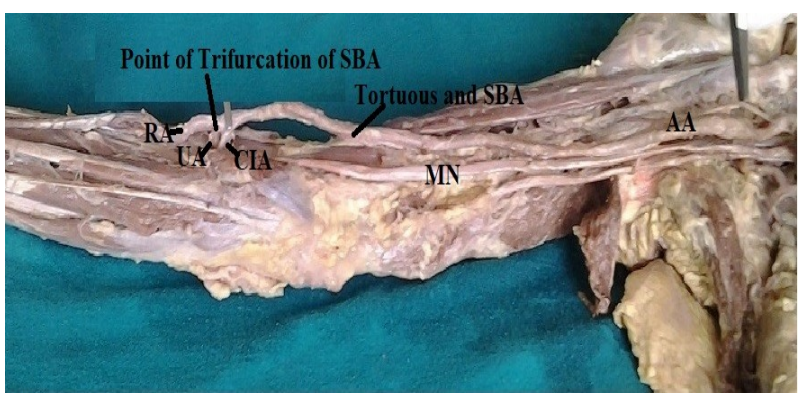

Table 4: Comparison of Incidence of Trifurcation of Superficial Brachial Artery (SBA).

\begin{tabular}{|c|c|c|c|c|}
\hline S No. & Author & Year & $\begin{array}{l}\text { No of } \\
\text { Limbs }\end{array}$ & $\begin{array}{c}\text { Trifurcation of } \\
\text { SBA (\%) }\end{array}$ \\
\hline 1 & Huber [31] & 1930 & - & - \\
\hline 2 & Lockhardt and Hamilton [32] & 1959 & - & - \\
\hline 3 & Malcic-Gurbuz et al. [36] & 2002 & - & 1case \\
\hline 4 & Patnaik et al. [35] & 2002 & 50 & $2 \%$ \\
\hline 5 & Bilodi \& Sanikop [33] & 2004 & - & 1 Case \\
\hline 6 & Vollala et al. [34] & 2008 & - & - \\
\hline 7 & Shivanal et al. [15] & 2015 & 50 & $10 \%$ \\
\hline 8 & $\begin{array}{l}\text { Murugapermal \& } \\
\text { MelaniRajendran [14] }\end{array}$ & 2014 & 50 & $2 \%$ \\
\hline 9 & Jayasree \& Reddy [16] & 2017 & 50 & $94 \%$ \\
\hline 10 & Present Study & 2019 & 56 & $1.78 \%$ \\
\hline
\end{tabular}

\section{DISCUSSION}

As depicted from Table 2, the results of incidence of normal brachial arteries were compared with different studies that ranged from lowest incidence of $77 \%$ to highest incidence $96 \%$ which was reported by Murugapermal $G$ and MelaniRajendran (2014) [11-15]. In the present study, percentage of normal brachial artery was found to be $94.64 \%$ that supports the findings of Jayasree \& Reddy (2017) [16].

Arterial variations are common in the upper extremity. The mechanism of development of arterial variations has been the subject of many studies. Usually, the brachial artery passes deep to the median nerve from the medial to the lateral side in front of the arm. But when it crosses the median nerve superficially and replaces the main trunk, it is termed as the superficial brachial artery $[17,18]$. The superficial brachial artery may replace the main trunk as seen in the present case. (Figure 1,2) Though, it may be accompanied by an equally important, less important or more important trunk running parallel and deep into the median nerve in the normal position [17]. These superficial brachial arteries may continue in the cubital fossa and bifurcate as usual into the radial and the ulnar arteries, both running a superficial course in the forearm [19] with the deep division continuing in the forearm as the Interosseous complex [20]. Singla and Lalit (2011) threw a flood of light on the earlier literature which was related to this entity andwas reported to vary between $0.2 \%$ to $22 \%$ [18]. Superficial Brachial Artery earlier has been reported as $6.0 \%$ by Poirier (1886), Linell (1921) and Patnaik et al. (2002), 5.0\% by Kapur et al. (2000) and Kachlik et al.(2011), 12.2\% by Yang et al (20081) [13,21-25]. However SBA was also reported by Nakatani et al. (1996), Kaur et al. (2011) and Alfaouri-Kornieieva (2013)[26-28]. According to Singer (1933) and Baeza et al. (1995) the brachial artery has got two trunks of origin. One is passing deep to median nerve and other superficial to the median nerve i.e. the superficial brachial artery. During later stages of development usually the deep artery gets haemodynamic preference leading to obliteration of superficial brachial artery located proximal to anastomosis, While the distal segments persist as a part of the radial artery. However if the artery passing superficial to median nerve gets the haemodynamic preference (as in the present case) the superficial brachial artery persists while the deep (Normal) one disappears $[29,30]$.

However, In the present study brachial artery showed different terminations in two upper limbs of same body. (Figure 3, Table 4) In the right upper limb there was no deep component and the superficial brachial artery itself terminated into the radial, ulnar and common interosseous arteries which were observed tortuous also. Both ulnar and radial were running superficial to superficial flexor group of muscles and common interosseous artery was running deep to superficial flexor group of muscles, whereas in the left upper limb, brachial artery bifurcated normally into ulnar, and radial arteries. Trifurcation of brachial artery into radial artery, ulnar artery and common interosseous artery observed in the present study was also reported by Huber (1930), Lockhardt \& Hamilton, (1959), 
Romanes (1964), Williams et al., (1999), Bilodi \& Sanikop, (2004) and Vollala et al., (2008) [2,10,31-34].

According to Huber (1930) supernumerary branches accessory to usual branches may arise from brachial artery which may also give origin at its bifurcation to common interosseous artery or to the median artery as the third branch and radial recurrent branch of radial may arise from distal part of brachial artery which also included its bifurcation [31]. William et al (1999) have mentioned under variations of brachial artery, that the brachial artery may bifurcate proximally and reunite to form single trunk or sometimes, trifurcate proximally into ulnar, radial, and common interosseous arteries [2]. Trifurcation in the middle of the arm instead of cubital fossa has also been reported [14]. Patnaik et al (2001) have also found radial recurrent artery as third branch in the trifurcation of brachial artery in a fifty years old male cadaver in one right upper limb, accounting for $2 \%$ [35].

Malcic-Gurbuz et al., in 2002 also observed a case of trifurcation of brachial artery into radial, ulnar and superior ulnar collateral arteries high up in the arm [36]. However reported trifurcation of brachial artery in $10 \%$ of cases [15].

Bilodi \& Sanikop (2004) also reported a case of brachial artery trifurcation into ulnar, radial, and common interosseous arteries in left upper limb but the main artery was not a Superficial brachial artery as in the present case [33].

For, an origin of common interosseous artery from superficial brachial artery there is a slight modification in Baeza et al (1995) model of development of Human Brachio-antebrachial system. The superficial brachial artery before dividing into its two terminal branches (Stage II of Baeza et al 1995) gives a branch which joins the axial artery distal to origin of deep component of radial and ulnar arteries. Usually this component also disappears as the haemodynamic preference goes for the deep component of axial artery. But in the present case (Figure 3 ) this component persisted and deep component disappeared leading to an origin of common interosseous artery from supe- -ficial brachial artery [18,30]. In the present study we observed loops and acute bends of the SBA, radial and ulnar arteries which may occlude the vessels causing ischemia. Variations in this study are significant because tortuous SBA with kinked origin of radial and ulnar arteries running a tortuous course may result in clinical emergency if medical personals are unaware of this type of variation. Artery which also included its bifurcation [31]. William et al (1999) have mentioned under variations of brachial artery, that the brachial artery may bifurcate proximally and reunite to form single trunk or sometimes, trifurcate proximally into ulnar, radial, and common interosseous arteries [2]. Trifurcation in the middle of the arm instead of cubital fossa has also been reported [14]. Patnaik et al (2001) have also found radial recurrent artery as third branch in the trifurcation of brachial artery in a fifty years old male cadaver in one right upper limb, accounting for $2 \%$ [35].

Malcic-Gurbuz et al., in 2002 also observed a case of trifurcation of brachial artery into radial, ulnar and superior ulnar collateral arteries high up in the arm [36]. However reported trifurcation of brachial artery in $10 \%$ of cases [15].

Bilodi \& Sanikop (2004) also reported a case of brachial artery trifurcation into ulnar, radial, and common interosseous arteries in left upper limb but the main artery was not a Superficial brachial artery as in the present case [33].

For, an origin of common interosseous artery from superficial brachial artery there is a slight modification in Baeza et al (1995) model of development of Human Brachio-antebrachial system. The superficial brachial artery before dividing into its two terminal branches (Stage II of Baeza et al 1995) gives a branch which joins the axial artery distal to origin of deep component of radial and ulnar arteries. Usually this component also disappears as the haemodynamic preference goes for the deep component of axial artery. But in the present case (Figure 3 ) this component persisted and deep component disappeared leading to an origin of common interosseous artery from superficial brachial artery $[18,30]$. In the present study we observed loops and acute bends of the 
SBA, radial and ulnar arteries which may occlude the vessels causing ischemia. Variations in this study are significant because tortuous SBA with kinked origin of radial and ulnar arteries running a tortuous course may result in clinical emergency if medical personals are unaware of this type of variation.

The upper limb arteries form an initial capillary plexus that appears from the dorsal aorta and develops at the same rate as the limb. A remodelling process occurs involving the enlargement and differentiation of selected parts [12]. Arey (1957) is of view It is thought that variations arise through the persistence, disappearance, incomplete development and fusions enlargement and differentiation of parts of the initial network which would normally remain as capillaries or even regress [37]. Injection studies on animal embryos and experimental data, showed that when an endothelial tube gets a muscular coating it loses its remodelling ability [38]. Most of vascular variations can be understood in context of vascular embryology. These deviations frequently resemble patterns found in the lower animals because embryology reflects evolution. In terms of phylogeny, Superficial Brachial Artery is a atavistic condition usually seen in primates and many of variations noted in man represent a retention or reappearance of primitive patterns which is in consonance with the view that ontogeny repeats phylogeny [39].

\section{CONCLUSION}

The superficial brachial artery as well as the superficial position of the ulnar and the radial arteries or tortuosity not only makes them more vulnerable to trauma and thus to bleeding, but also makes them more accessible to cannulation, if needed. These arteries may also be mistaken for veins. Moreover, if the superficial brachial artery is retained, it is usually associated with a retarded development of the palmar arch. The trifurcation of brachial artery in the lower part of arm may result in excessive hemorrhage during supracondylar fracture of the humerus. A lack of knowledge of such type of variations with different patterns may complicate the surgery and may cause unnecessary bleeding. Therefore, overall understanding of normal pattern of brachial artery, its branching pattern and its variations is essential for the clinicians and surgeons to avoid iatrogenic injuries, for accurate diagnostic interpretation and therapeutic intervention so as to reduce morbidity and mortality.

\section{Conflicts of Interests: None}

\section{REFERENCES}

[1]. Standring S, Borely NR, Collins P, Crossman AR, Gatzoulis MA, Herly JC, et al. Gray's Anatomy: The Anatomical Basis of Clinical Practice. Upper arm. 40th Ed, London: Elsevier Ltd; 2008;Pp:827-836.

[2]. Williams PL, Bannister LH, Berry MM, Collins P, Dyson M, Dussek JE, Ferguson MWJ. Gray's Anatomy In: Arteries of the limbs \& Cardiovascular System. Gabella, G. Edr. 38th Edn. Churchill Livingstone, New York: 1999;Pp:1537-44.

[3]. Singh H, Gupta N, Bargotra RN, Singh NP. Higher bifurcation of brachial artery with superficial course of radial artery in forearm: case report. JK Science. January-March 2010;12(1);39-40.

[4]. Holinshed W H. Anatomy for surgeons: vol.3 (The Back And Limbs). Third Edition, Philadelphia, Harper \& Row 1982;Pp:366.

[5]. Hazlett JW. Superficial ulnar artery with reference to accidental intra-arterial injection. Canadian Medical Association Journal 1948;61:289-93.

[6]. Pabst R and Lippert H. Beiderseitiges vorkommen von A. brachialis superficialis, Ulnaris superficialis and A. mediana. Anatomischer Anzieger 1968;123:223-226.

[7]. Jurjus A, Sfeir R and Bezirdjian R. Unusual variation of arterial pattern of the human upper limb. Anat Rec.1986;215:82-83.

[8]. Bazemore E, Mann JT. Problems and complications of the transradial Approach for Coronary Interventions: A review. J Invasive Cardiol 2005 Mar;17(3):156-9.

[9]. Hunq YC, Yen HL, Vincent-wu, I-Jung Tsai, Dunwu K, Juey JH.Nephrology dialysis transplantation. Oxford journal of medicine. 2005; 20(11):2579-80.

[10]. Romans GJ. Cunningham's Textbook of Anatomy. In: The Blood Vascular System. Arteries of the upper limb. Walls, E.W. Edr. 10th Edn. Oxford University Press, New York: 1964;Pp: 885-893.

[11]. Uglietta JP, Kadir S. Angiographic study of variant arterial anatomy of the upper extremities. Cardiovasc Int Radiol 1989;12:145-8.

[12]. Rodriguez-Niedenführ M, Vazquez T, Nearn L, Ferreira B, Parkin I, Sanúdo JR.Variations of the arterial pattern in the upper limb revisited: a morphological and statistical study, with a review of the literature. J Anat 2001;199:547-66.

[13]. Patnaik VVG, Kalsey G, Rajan KS. Branching pattern of brachial artery-A Morphological Study. J Anat. Soc India 2002;51:176-86. 
[14]. Murugapermal G and MelaniRajendran S. Study of trifurcation of brachial artery. Int J Curr Microbiol App Sci 2014;3(9):897-901

[15]. Shivanal U, Gowda M S T. A study of variations in brachial artery and its branching pattern. Int J Res Med Sci 2015;3(6):1392-1396

[16]. Jayasree C, Reddy CK. A Cadaveric study on variations in brachial artery - An Anatomical Perspective. Perspectives in Medical Research 2017;5(2):2932.

[17]. Adachi B. Arteriensystem der Japaner. Kyoto, Verlag der Kaiserlich-Japanischen Universitatzu Kyoto 1928;205-210.

[18]. Singla RK and Lalit M. Superficial Brachial Artery with a High Origin of ProfundaBrachii and Common Interosseous Artery: A Case Report. Journal of Clinical and Diagnostic Research 2011;5(3):628630

[19]. Keen JA. A study of arterial variations in limbs with special reference to symmetry of vascular patterns. Am J Anat 1961;108:245-261.

[20]. Vare A M and Bansal P C. A case of anomalous brachial artery and other associated vascular anomalies in a single upper limb. J Anat Soc Ind 1969;18(2):50-53.

[21]. Poirier P. Traite de Anatomie Humans Vol. II Battaille \& Co. Paris. 1886;Pp:756.

[22]. Linell EA. The distribution of the nerves in upper limb with reference to variability \& their clinical significance. Journal of Anatomy. 1921;55:79.

[23]. Kapur V, Suri RK, Manik P and Dhir V. Surgical anatomy of median nerve. Journal of the Anatomical Society of India 2000;49(1):92.

[24]. Yang HJ, Gil YC, Jung WS, Lee HY. Variations of the superficial brachial artery in Korean cadavers. J Korean Med Sci 2008;23:884-887.

[25]. Kachlik D, Konarik M, Baca V. Vascular patterns of upper limb: an anatomical study with accent on superficial brachial artery. Bosn J Basic Med Sci 2011;11(1):4-10.

[26].Nakatani T, Tanaka S, Mizukami S, Shiraishi Y, Nakamura T. The superficial ulnar artery originating from the axillary artery. Ann Anat 1996;178:2779.
[27]. Kaur N, Patnaik VVG, Singla RK. Bilateral superficial brachial artery - a case report IJAV 2011;4:207210.

[28].Alfaouri-Kornieieva M. Persistent superĐicial brachial artery in humans. OA Case Reports 2013;2(5):49.

[29]. Singer E. Embryological patterns persisting in arteries of the arm. Anat Rec 1933;55:406-413.

[30]. Baeza RA, Nebot J, Ferreira B, Reina F, Perez J, Saundo J.R. et al. An Anatomical study and ontogenic explanation of 23 cases with variations in main pattern of brachioantebrachial arteries. J Anat 1995;187(2):473-479.

[31]. Huber GC. Piersol's Human Anatomy. In: The Vascular system. 9th Edn. Vol. I J.B. Lippincott. Co. Philedelphia 1930;Pp:767-791.

[32]. Lockhardt RD, Hamilton GF. and Fufe FW. Anatomy of the human Body In: Vascular System- Systemic arteries. Faber \& Faber Ltd.; London 1959;Pp:612619.

[33]. Bilodi AK, Sanikop MB. Variations in termination of brachial artery - a case report. Kathmandu Univ Med J 2004;2(1):49-51.

[34]. Vollala VR, Nagabhooshana S, Bhat S M. Trifurcation of brachial artery with variant course of radial artery: Rareobservation. Anat. Sci. Int 2008;83:307 309.

[35]. Patnaik VVG, Kalsey G, SinglaRajan. Trifurcation of Brachial artery-A case Report- Journal of Anatomical Society of India. 2001;50(2):163-165.

[36]. Malcic-Gurbuz J, Gurunluogl R, Ozdogmus O, Yalin, Aymelek A. Unique case of trifurcation of the brachial artery: its clinical significance. Clinic Anat 2002;15(3):224-7.

[37]. Arey LB. Developmental Anatomy. In: Development of the arteries. 6th Edition. W.B Saunders Co, Philadelphia; 1957;Pp:375-377.

[38]. Rodriguez-Niedenführ M, Vazquez T, Parkin IG, Sanudo JR. Arterial patterns of the human upper limb: update of anatomical variations and embryological development. Eur J Anat 2003;7:21-8.

[39]. Smith MT. The limb arteries of primates. J Anat Physiol 1910;45:23-64.

How to cite this article:

Monika Lalit, Sanjay Piplani. A cadaveric study of brachial artery and its variations with its ontogenic basis: An Anatomical Perspective. Int J Anat Res 2021;9(1.1):7844-7850. DOI: 10.16965/ ijar.2020.233 